\title{
An Integrative Thematic Textbook for Higher Education Based on Ethnopedagogy
}

\author{
Ganes Gunansyah, Neni Mariana, Suprayitno \\ Universitas Negeri Surabaya \\ Surabaya, Indonesia \\ ganesgunansyah@unesa.ac.id
}

\begin{abstract}
This paper aims to present the development of integrative thematic textbook based on ethnic-pedagogic studies. The textbook is created to fulfill the gap between the curriculum in Indonesian elementary schools and the curriculum in Department of Elementary Teacher Education in university. The Indonesian elementary school curriculum required integrative learning of multiple subjects within a theme, whereas in the university level prospective primary school teachers are learning the disciplines separately. This integrative thematic approach makes an urge for the university to prepare the model of textbook which is used by undergraduate students in higher education as an example of conducting integrative learning. Ethno-pedagogic studies are conducted to identify appropriate themes for the book. The initiated ethno-pedagogic themes are used as a unique property of the book which can integrate linking competencies from many different subjects. The first-year research of book design shows that the themes are powerful to compile various disciplines of several chosen lectures (social studies, mathematics, science, Indonesian language and art) in higher education. The second year of this study used experimental research design and it found that the book is considered to be appropriate to use for undergraduate students in the department of elementary teacher education.
\end{abstract}

Keywords-ethno-pedagogy; integrative thematic approach; textbook; higher education

\section{INTRODUCTION}

The application of curriculum learning in elementary school not make packed with partial but rather integrated (thematic integrative) through sets of themes [1]. It makes various units of education including primary school is currently facilitated by the Government with the teacher and the student book based themes [2]. However, it is inversely proportional to the implementation in the Department of teacher education primary School as producers of primary school teachers in which the curriculum and learning practices implemented in partial accordance fields of study or clumps and not yet supported by the example of model of a textbook cross-field studies [3].

Therefore, to be able to accommodate the learning material from various fields of study consisting of the natural sciences, social sciences, mathematics, arts and culture and creating handicraft, as well as the Indonesian Language. Required textbook cross literacy-based fields of study. Literacy-based learning can connect essential concepts from different areas of study are presented. Because there is no field of study that did not require literacy activities that are capable of making learners actively involved and participate to find and manipulate data and make use of information to solve problems in daily life [4]

In addition, based on the guidelines close to learning (learning outcomes)-based curriculum KKNI (Indonesia National Qualifications Framework), one of the main competence attached to the student graduates Strata one primary school teacher education that is able to appreciate the diversity of cultures, viewpoints, religion and belief, work together and have the social, as well as having concern for society and the environment. In order to meet the demands of cereal, then cross the literacy-based field of study can benefit from ethno-pedagogic materials, namely a study that presents values wisdom and excellence of local (local genius/local wisdom) [5].

Through the study of ethno-pedagogic, any area of study can be dug up, identified, and utilized the concept or materials that are relevant to the field of its. For example, like mathematics, can take advantage of the object/objects that support the traditional realistic mathematics learning (PMRI) connected with everyday life or called with ethno-mathematic. Ethno-mathematics is an approach that is used to describe the reality of the relationship between cultural environment and math while delivering learning in class. For example, teachers can benefit from a jump rope game that uses a series of rubber band for teach measurement of length. Similarly, in natural science (Biology) or called with ethnoscience, can take advantage of various ways of conservation of nature and the type of plants that can be used as a traditional remedy that's been passed down from one generation to the next generation. In the social sciences or ethnographic study is understanding about the cultural phenomena that reflect the knowledge and systems of meaning group of cultural groups. There are ethnolinguistic in the language and in the art of music (ethnomusicology) is the study of the study of music in culture.

Local wisdom is also interpreted as a view of life and knowledge as well as many disembodied life strategy activities conducted by local communities in answering the various problems in the fulfillment of their needs. In the present context, due to the insistence of the modernization and globalization of local wisdom-oriented (1) the balance and 
harmony of man, nature, and culture; (2) sustainability and diversity of nature and culture; (3) conservation of natural resources and cultural heritage;(4) a saving of valuable economic resources; (5) morality and spirituality. The themes of such orientation very relevant for ideals, paradigm, and sustainable development planning [6]. Another opinion expressed, that the ethno-pedagogic is a practice-based education local wisdom in various aspects and emphasize local knowledge or wisdom as a source of innovation and skills that can be used for the welfare of the community; local wisdom is related to how knowledge is generated, stored, managed, and implemented, inherited [7].

Furthermore, the development of model-based literacy textbook study of ethno-pedagogic developed are meant to be used as (a) reference materials, (b) feedback for clumps of courses in repairing and improving the quality of learning is nothing particularly in primary school teacher Education Faculty of Education University of Surabaya, (c) gives the implication of pedagogy students as prospective elementary school teacher in order to observe and interpret the values local wisdom.

\section{THEORETICAL REVIEW}

\section{A. The role of the Textbook in Learning}

The textbooks or learning materials was cast as one of supporting the development of quality process variables that the fact is that interaction between educators and learners [8]. Therefore, the content of textbooks which do not comply with the requirements of the learning process may cause the failure of an instruction. Through the learning materials that the concepts are intertwined and integrative nature lets bring up various stimulant for the learners can be facilitated to make observations to proceed with the activity of reasoning. So that learners can be facilitated reasoning activities properly, then it should be adjusted with the local wisdom that exists around the residence. The following explanation of local wisdom.

\section{B. Local wisdom}

Local wisdom is defined as a view of life and knowledge as well as many disembodied life strategy activities conducted by local communities in answering the various problems in the fulfillment of their needs [9]. In the present context, due to the insistence of the modernization and globalization of local wisdom-oriented (1) the balance and harmony of man, nature, and culture; (2) sustainability and diversity of nature and culture; (3) conservation of natural resources and cultural heritage; (4) a saving of valuable economic resources; (5) morality and spirituality. The themes of such orientation very relevant for ideals, paradigm, and sustainable development planning

\section{METHOD}

This research use approach Research \& Development using the design of the 10 stages of Borg \& Gall [10]. The purpose of the activities in phase 1 is to examine and identify the constraints or obstacles, the fact that occur as well as the hope of improvement and perfection about the lectures in the Department of teacher education elementary school. Activities performed include (1) surveys and observations of the needs analysis, the analysis of the observational constraints directly related practices class lectures and mastery of the competencies students by conducting interviews with lecturers and students in the Department of Primary School Teacher Education. In-depth interview against student-related activities and associated costs, needs, wants and expectations of an attempt to optimize the students ' competence in designing and applying of the learning-oriented scenario development. While the analysis of constraints will be reflected on the problems faced by a lecturer in pedagogy and professional ability, particularly in helping the achievement of student competencies in quality development activities lectures; (2) review of theories related to the concepts of education and learning field of study in elementary school, support the theory of ethno-pedagogic, ethnolinguistic, ethnomathematics, ethnomusicology in the Department of teacher education elementary school.

Furthermore, activities focused on validation experts. Test experts include expert education to primary schools, Education experts or field of study, and ethnographer or anthropologist. Next, do a limited test model ethno-pedagogic based literacy textbooks through the utilization of local genius as social capital to improve the competence of students in the primary school teacher Education Majors. This limited field test to unearth input on the feasibility of the product ethnopedagogic based literacy textbooks through the utilization of local genius as social capital to improve the competence of students in the primary school teacher Education Majors from the side of the users, i.e. the Faculty and students of primary school teacher education. The next activity was a revision of a product based on the test results is limited.

\section{RESULTS AND DISCUSSION}

Textbook model of cross-field-based study ethnopedagogic is a book that is used to enrich the textbook used at lecturing students in major stratum one primary school teacher education. Several phases of analysis has been done of them: (1) phase of the design and selection of the format of the textbook model; (2) an analysis of the development model of textbooks which consists of descriptions of the chapter and the chapters, bibliography, glossary, index; (3) an analysis of the characteristics of the fill material, including material identification model of textbooks, the contents of the textbook, compiled mapping themes and sub-themes, compose the structure of the textbook; (4) an analysis of the learning resource, in the form of identification of the availability, suitability, and ease of support different types of learning resources; and (5) needs analysis for professors and students.

Based on the results of the needs analysis obtained some findings in the form of advice, both from the target students or lecturers cross clumps of courses or majors in the Department of education of primary school teachers in mind some aspects regarding the components of the curriculum and learning conceived $100 \%$ of the students in the form of textbook/textbook, the number of courses and time hours 
lecture. Then about the ability of a student, lecturer, capabilities and load units of Credit courses each registration $(89 \%),(87 \%),(86 \%)$. While understanding the lowest of the standard of competence or in terms of the National Qualifications Framework curriculum Indonesia or referred to as close to learning (learning outcomes). A good understanding of textbooks or textbook showed that students argued that the curriculum and implementation of learning is closely associated with the presence of textbook or textbook.

In addition, a number of obstacles still encountered in the implementation of the curriculum in the Department of teacher education elementary school i.e. solid curriculum content as well as the limited availability of textbooks or textbook that supports against the activity of the lecture, that each registration (92\%) and (90\%). While the lack of a concept of linkages between courses or study material in lectures as well as a lack of learning materials development based on local wisdom (ethno-pedagogic) is the next obstacle perceived student, i.e. each registration (49\%) and (34\%).

When associated with the understanding of students regarding a selection on a variety of thematic or integrated learning model relevant to the needs of teaching in primary schools included in the lectures in the education of primary school teachers in mind Understanding student learning model on various thematic/integrated already good i.e. each shared $(62 \%)$, integrated $(55 \%)$, connected $(32 \%)$, webbed $(24 \%)$, and networked (18\%). This indicates that the model integrated and connected relevant model is an option for teaching in elementary school due to being able to integrate a variety of concepts presented though from various quiz/competence base.

The expected support in optimizing student learning practices is a conceptual representation and practice in integrated learning $(100 \%)$, satisfy competencies or learning nothing $(100 \%)$, development of integrated between knowledge, skills, and attitudes (100\%). While the next expectation about support materials including textbooks relevant registration $(83 \%)$.

While obstacles still encountered in practice lectures especially on integrated learning courses in the Department of teacher education elementary school students known to have argued that the success of the integrated learning need to be supported the existence of a suitability of learning experiences during the lecture in the Department of Education elementary school teacher with the demands of teaching in primary schools (97\%), presence of textbooks that contain examples of the application of integrated learning and applicative integration concept from different study of essential concepts. each registration $(75 \%)$ and $(65 \%)$. This indicates that the students as the main offender learning in addition to lecturers have confidence and hope that the presence of the applicable textbook as well as the suitability of the learning experience gained with the demands of the teaching in elementary school is an immediate need.

With regard to efforts to upgrade student Educator elementary school teacher in integrated learning application of mastery known students expect the use of thematic learning model relevant to the demands of the field at the school Basis, registration $(93 \%)$, the interconnectedness of various source materials of cross-field of study or a clump of courses, i.e. registration $(90 \%)$, the delights of the applicative is a way to combine the learning of essential concepts close to the charge that there is on each quiz through the bond theme, i.e. registration $(89 \%)$, as well as how to integrate the charge material with dishes of local wisdom or ethno-pedagogic, i.e. registration $(82 \%)$.

This shows at once bracing that the students willed that the presentation of the material is not presented separately as if the lack of a concept of relatedness to each other but instead expect a thorough understanding of the whole, as well as mutual related each other. As the accumulation of a series of questions that have been well known that almost needs analysis, most students agree the need for model textbooks in primary school teacher Education Majors. registration (83\%). While the need for availability of model sample textbook cross courses (thematic) that can be utilized in lectures in the Department of teacher education elementary school showed that the entire student respondents $(100 \%)$ to feel the needs and the demands will be the presence of a textbook example of a model can facilitate the understanding of the concept of integrated students against cereal material cross fields of study/review materials or clumps of courses.

The opinion of students regarding textbook examples of models of cross-subject areas or courses will be developed to load local wisdom or ethno-pedagogic studies relevant to learning in elementary school known to most (almost 93\%) students expect a model thematic textbooks will be compiled and developed can load a variety of local wisdom or charge is ethno-pedagogic. Student opinions regarding related preparation of a sample textbook model known to students wanting the development and preparation of thematic textbook model needs to pay attention to the distribution of competence of each standard courses to be packed in close to the mapping learning.

While based on responses to a lecturer subjects feel the process of lectures and student learning outcomes in certain subjects, particularly with regard to the development of practice-oriented education (local wisdom ethno-pedagogic) not optimal dug and developed. This is due to the presence of an intact yet understanding and thorough study of the urgency and relevance against ethno-pedagogic against the development in every field of study that includes the natural sciences (ethnoscience), Social Science (ethnography), Math (ethno-mathematic), (ethnolinguistic), music (ethnomusicology). The charge of the material presented on the respective subjects or areas of study still partial and yet the existence of the concept of connectedness (connected).

This is of course in addition to strengthening students ' insight is also needed against the thematic study integrative aligned with the needs of a school that had long been implementing thematic Learning curriculum through 2013. Therefore, through the analysis of the needs of lecturers and students, it is known that the availability of learning resources which thematic learning reduce integrative indispensable to reach its demands and challenges, both at the college level high school or elementary school level including. The results 
of your views, suggestions, and input the student, aware that students are basically feel the need the newer model sample textbooks can reinforce an understanding of integrative thematic learning is needed later in the praxis in landscape Elementary School. In addition, through the presence of a model of textbook that contains cross-majors or courses, student mastery against the concept of linkages in each study is believed to be better.

The results of the needs analysis next made reference to material composing and developing the draft structure and Systematic of writing the draft model textbooks. As for the results achieved among them include (1) the identification of the relevant literature review, (2) mapping LO and CLO at the respective courses, (3) determining appropriate linkages theme concept on LO and CLO, (4) preparation of draft themes in it contains the concept of relatedness (thematic integrative) CLO on some subjects that are relevant.

Model of the finished textbook made further votes disqualified by experts. The feasibility assessment refers to assessment of textbooks according to National Professional Certification Agency. The results of the review of the content and media experts stated that the textbook model based ethnopedagogic been developed in accordance with the characteristics of students of primary school teacher education. In General, the feasibility of the linguistic content, components, and graphic dishes are already expressed very well. Experts study media expert content and give you some advice and commentary on the refinement of the text materials, among them (1) on the graphics component, especially in the management aspects of the layout, illustration and graphic design the look still needs fixing in order for the students as the main user became more interested and motivated to explore the entire cereal content of learning materials; (2) examples of ethno-pedagogic charge can directly with appropriate materials serving the field of study or course

While expert instructional design to give advice and commentary on the consummation of this festive, namely (1) illustrations, drawings and photographs in order to be served more diverse and interesting; (2) the layout and the combination of tinting to note when printing. The following summary of the results of the validation are presented as follows.

TABLE 1. SUMMARY OF THE RESULTS OF VALIDATION EXPERTS

\begin{tabular}{|c|c|c|c|c|c|}
\hline \multirow{2}{*}{$\begin{array}{c}\mathrm{Nu} \\
\mathrm{mb} \\
\mathrm{er}\end{array}$} & \multirow{2}{*}{$\begin{array}{l}\text { Aspects that } \\
\text { are assessed }\end{array}$} & \multicolumn{3}{|c|}{ The average score validator } & \multirow{2}{*}{$\begin{array}{l}\text { Aver } \\
\text { age }\end{array}$} \\
\hline & & $\begin{array}{l}\text { exper } \\
\mathrm{t} \\
\text { mater } \\
\text { ial }\end{array}$ & $\begin{array}{l}\text { Media } \\
\text { expert }\end{array}$ & $\begin{array}{c}\text { Media } \\
\text { Expert } \\
\text { educatio } \\
n \\
\text { (ethno- } \\
\text { pedagog } \\
\text { ic) }\end{array}$ & \\
\hline 1. & $\begin{array}{l}\text { The } \\
\text { eligibility of } \\
\text { the contents }\end{array}$ & 3,6 & 3,5 & 3,5 & 3,53 \\
\hline
\end{tabular}

\begin{tabular}{|c|c|c|c|c|c|}
\hline 2. & The linguistic & 3,6 & 3,5 & 3,6 & 3,56 \\
\hline 3. & Display & 3,5 & 3,5 & 3,6 & 3,53 \\
\hline 4. & Graphic & 3,6 & 3,6 & 3.5 & 3,56 \\
\hline
\end{tabular}

Overall learning materials developed are already eligible to be used with a small revision.

\section{Discuss}

Textbook model of cross-field-based study ethnopedagogic developed through this research is oriented at strengthening learning in lectures in the Department of Strata one primary school teacher education-based thematic or integrated. In accordance with the constraints encountered, namely (1) the presentation of a lecture which is still partial, (2) integrated learning courses has not been optimally facilitate presentation of applicative example lecture material that integrates both the essential concepts in the bond theme, ( 3) yet the availability model sample textbook cross-field of study or course lectures. Based on these constraints, external in research focused on eliminating the gaps while adjusting the needs on the ground, in this case, demands the implementation of a curriculum that requires the 2013 school learning Basic integrative served in the bond theme.

Based on the results of the analysis note that student understanding again aspects of the curriculum specifically regarding support availability of reference or textbook entirely deliver its needs. The textbooks or learning materials was cast as one of supporting the development of quality process variables that the fact is that interaction between educators and learners [8]. With constraints of implementing the curriculum and learning. the limited textbooks or the limitation of the textbook supporting relevant activities and associated costs. The constraints due to only a few lecturers courses has compiled itself and use the textbook or the text in the lecture activity while almost new largely limited to providing information resources to students. The textbooks which do not comply with the requirements of the learning process may cause the failure of learning [8].

Additionally, students felt the lack of linkages between servings of concept courses. This causes difficulty obtaining students examples of how matter in the delights of the applicative lectures can be a learning experience for application of learning in the future after they graduated and taught at the basic education level. Scientific concepts are studied should be obtained through direct experience and relate it to other concepts that are already understood [11]. Other constraints in the form of lack of learning materials development based on local wisdom (local genuine). This resulted in the student cannot relate the conceptual theoretical knowledge obtained with the knowledge and experience that have been owned in everyday life which is authentic and contextual. For example, with regard to the potential of that gap, natural Science Learning by using ethno-since-based module, students will be more interested and enthusiastic towards learning. This study aims to introduce to the students that the existence of facts or phenomena that develop in a 
society can we associate with science scientific materials that exist as a science [12].

In addition to contextual learning, strengthening the representation of the charge material with wisdom and excellence can grow local characters. Character study is also owned by the entire field of study both Social Science, natural science, mathematics, arts and crafts, educational civics and citizenship, language and other educational subjects. In the planning stages as well as implementation, learning loads of character and local wisdom-based material fact is a combination of various essential concepts, either the social sciences, natural sciences, and the Humanities which is associated with concepts of education in a systematic, psychological and functional in accordance with the level of development of good moral, cognitive, and social-learners. Through examples of symptoms or phenomena, both with regard to the social as well as associated between natural and social will be interesting and important thing learned by learners. Different types of questions, both of which are factual, productive as well as imaginative can be excavated and explored for purposes of learning activities. To introduce a wide range of natural or social phenomena, various stimulus ranging from pictures, video footage, newspaper articles and direct observation can be presented and introduced in elementary school age children. Through the learning materials that the concepts are intertwined and integrative nature lets bring up various stimulant for the learners can be facilitated to make observations to proceed with the activity of reasoning. On the stages of observation, students can be asked to find various things that are factual or what it is appropriate that the stimulant is in contain, a temporary stage of reasoning can be developed through the question of causality (cause and effect) or to predict the various possibilities that arise.

The purposes of recognizing and understanding a phenomenon or symptom is intended as an attempt to explore and develop a number of potential base belonging to children, including the potential curiosity (sense of curiosity), want to see the reality (sense of sense of reality), would like to find (a sense of inquiry) and want to find (the sense of discovery). The fact that every incident in the natural or social life always does not separate or stand-alone from other elements but rather always related and very complex. Next to that is through a textbook model of cross-subject areas or courses, any symptoms or events will be continually discussed and approached in order to be recognized, understood, resolved and we appreciate the meaning behind them, one of them by digging and find local wisdom values (local wisdom).

Local wisdom is also interpreted as a view of life and knowledge as well as many disembodied life strategy activities conducted by local communities in answering the various problems in the fulfillment of their needs. In the present context, due to the insistence of the modernization and globalization of local wisdom-oriented (1) the balance and harmony of man, nature, and culture; (2) sustainability and diversity of nature and culture; (3) conservation of natural resources and cultural heritage; (4) a saving of valuable economic resources; (5) morality and spirituality. The themes of such orientation very relevant for ideals, paradigm, and sustainable development planning.
When associated with the practice of integrated learning or thematic material, charge-based local wisdom is learning that has an orientation in harmony and appropriate when combined, including in learning in elementary school. Through the integration of local wisdom values, learners are expected to develop knowledge, understanding, and skills to resolve the social problems that occur in everyday life. The learning process is not just a passive activity received the material, but rather the process of actively digging up old experiences, seek and find new experiences as well as assimilate and linking between the two thus forming meaning.

For example, in charge of basic competence social sciences subjects, one of which there is nothing regarding the "ability to explain the physical sustainability, culture and society as well as the relic of a change in the geographical aspects economy, culture and politics ". To achieve this, the competence will be particularly relevant when presented contextually by utilizing the multiple dimensions of culture that exists in East Java, including the charge contained elements of local wisdom as the superiority of their respective regions. East Java has ten different cultural regions, although in the same province. Based on the product and cultural character, the tenth region of the culture, that is territory of Javanese culture Mataraman, Ponoragan, Arek, Samin (Sedulur sikep), Tengger, Osing (Using), Pandalungan, Madura Island, Madura and Bawean, Kangean Island [13]. Each ethnic group has its identity and superiority or excess, both associated with the products and performance of the cultural. Advantage and the benefits can be used to support accelerated development in East Java, either physical or moral development-spiritual [13]. For example, a small community and Samin is known to have advantages in the form of honesty and a love of the great tradition as a buffer against their identity. Ponoragan Java community and Mataram was known to have excellence in the field of the arts, agriculture, and appreciation of traditional values that are constructive. Arek community known to have advantages in terms of ownership determination, solidarity, and the high spirit of egalitarianism.

To help give an understanding about the form of local wisdom, learners can be facilitated by reading various articles from newspapers (online or offline) as well as magazines and other sources. For example, presenting information about the local wisdom in Banyuwangi, East Java tourism area. After reading the blurb, the activity can proceed with identifying some tribal communities or practice activity Osing in trying to adapt to the local environment by keeping hold of the ideas of the local (local) that are full of wisdom, discernment, good value, embedded and hereditary followed by members of the community. The form of the local wisdom is what ultimately became the hallmarks of the cultural community tribes $O$ sing thus became one of the favorite tourist destination of ecotourism, especially for foreign tourists.

In order to help further the introduction and understanding of local wisdom, learners can be helped by the granting of alternative activities. Stages of its activities can start with (1) digging up information from a variety of sources both online and offline on one aspect which has loads of local wisdom as a product of culture, natural resources, the activity of the 
community; (2) visit the place or location has the advantage of traditional activities with local observation and interview locals to dig in against the attitude or the views, beliefs, habits, daily practice.

Through the presence of a model of cross-field of study textbook based ethno-pedagogic (wisdom and excellence of local culture) next is expected to improve the competence of students of primary school teacher education as a potential primary school teachers to be able to innovative learning, designing, implementing, and assessing learning thematic integrative in elementary school.

\section{CONCLUSION}

Based on the research results obtained the following conclusions: (1) contributions derived from this research are causing the needs analysis and the analysis of the constraints that come from the students and lecturers Science education courses Social Knowledge Elementary School; (2) the structure of the model materials printed books Education Social Science elementary schools include: (a) the introduction, (b) section learning activities, (c) a list of the literature. The introduction contains a preface, table of contents, General description of the contents of the book, the relevance of each unit, course description, usage instructions textbook for college students. Content includes: content structure, exposure to the material, the activity "Let's read," alternative activities, exercise activities (nature of the individuals and groups), summary, formative test, signs a formative test answers, answer keys, glossary; (3) the results of the review of the expert content, media expert and expert study stating that textbook Social Science education of elementary school developed already in accordance with the characteristics of students of primary school teacher education which includes components appropriateness of content, linguistic, cereal, and graphic already expressed very well. This indicates that the student have confidence and hope that the quality of the lectures in the primary school teacher education can be enhanced with the presentation of the material is not just theoretical but rather conceptual applicative and the existence of the presence textbooks so that at its origin can facilitate them in achieving competence already contained in the learning product.

\section{REFERENCES}

[1] Braun V, Clarke V, Terry G. Thematic analysis. Qual Res Clin Health Psychol. 24;24:95-114, Oct. 2014.

[2] Yulianti K. The New Curriculum Implementation in Indonesia: A Study in Two Primary Schools. International Journal about Parents in Education. 1;9(1), Jan. 2015.

[3] Hart G. Information literacy education in disadvantaged schools: A case study of project work at a primary school in South Africa. School libraries worldwide.;5(1):78. 1999.

[4] Alvermann DE. Effective literacy instruction for adolescents. Journal of literacy Research.34(2):189-208, Jun. 2002.

[5] Rohadi T. Deradicalization Through Multicultural and Local Wisdom Literacies Based Teaching Model at Salaf and Kholaf Pesantren in West Java. Ijtimā'iyya: Journal of Muslim Society Research. 30;2(1):21-42, Mar. 2017.

[6] Brata IB. Kearifan Budaya Lokal Perekat Identitas Bangsa. Jurnal Bakti Saraswati (JBS);;5(1), 2016

[7] Alwasilah AC, Suryadi K, Karyono T. Etnopedagogi: Landasan praktek pendidikan dan pendidikan guru. Bandung: Kiblat Buku Utama. 2009.

[8] Tomlinson B. Challenging teachers to use their coursebook creatively. Creativity in the English language classroom.:24-8, 2015.

[9] Meliono I. Understanding the Nusantara thought and local wisdom as an aspect of the Indonesian education. TAWARIKH. 16;2(2), Mar. 2016.

[10] Gall MD, Borg WR, Gall JP. Educational research: An introduction. Longman Publishing; 1996.

[11] Makhrus M, Hadiprayitno G. Penerapan Perangkat Pembelajaran Fisika Berorientasi Pembelajaran IPA Terpadu Tipe Connected. Jurnal Pendidikan dan Pembelajaran (JPP). 15;19(2):237-42, Apr. 2013

[12] Nailiyah MR, Subiki S, Wahyuni S. PENGEMBANGAN MODUL IPA TEMATIK BERBASIS ETNOSAINS KABUPATEN JEMBER PADA TEMA BUDIDAYA TANAMAN TEMBAKAU DI SMP. Jurnal Pembelajaran Fisika. 1;5(3):261-9, Dec. 2016.

[13] Hadi N. Bringing Back Kasada Ceremony Identity in The Middle of State Religious Penetration at Tengger Community.2016 